\title{
Schwannoma of the intermediate nerve: A rare type of cerebellopontine angle tumor
}

\section{Schwannoma del nervio intermedio: Un tipo raro de tumor del ángulo pontocerebeloso}

\author{
Adriana Rodrigues Libório dos Santos MD. ${ }^{1,2,3}$, Silvia Mazzali Verst MD, PhD. ${ }^{4}$, Wilson Scappini Junior \\ MD. ${ }^{4}$, Pedro Henrique Simm Aguiar ${ }^{8}$, Aurélio Diniz ${ }^{8}$, Marcos Vinícius Calfat Maldaun MD, PhD. ${ }^{5}$, Paulo \\ Henrique Pires de Aguiar MD, PhD.,5,7
}

\author{
${ }^{1}$ Copa Star Hospital, Neurosurgery Department, Rio de Janeiro. RJ, Brazil. \\ ${ }^{2}$ State Brain Institute Paulo Niemeyer, Neurosurgery Department, Rio de Janeiro. RJ, Brazil. \\ ${ }^{3}$ Ipanema Federal Hospital, Neurosurgery Department, Rio de Janeiro. RJ, Brazil. \\ ${ }^{4}$ Sírio Libanês Hospital, Neurophysiologist, São Paulo. SP, Brazil. \\ ${ }^{5}$ Sírio Libanês Hospital, Neurosurgery Department, São Paulo. SP, Brazil. \\ ${ }^{6}$ Section of Post-Graduation Civil Servant State Hospital, São Paulo. SP, Brazil. \\ ${ }^{7}$ Department of Neurology and Neurosurgery Santa Paula Hospital, São Paulo. SP, Brazil. \\ ${ }^{8}$ BA Pontifical University Catholic of Sorocaba. SP, Brazil.
}

\begin{abstract}
Resumen
Antecedentes: El schwannoma del nervio intermedio es poco común. La mayoría de las lesiones del ángulo pontocerebeloso (APC) son schwannomas vestibulares. Descripción del caso: Mujer de 50 años que consulta por dolor de oído, parálisis facial e hipoacusia. La resonancia magnética reveló un tumor APC. Se realizó abordaje retrosigmoideo izquierdo y microcirugía y el origen tumoral fue del nervio intermedio. Se utilizó monitorización neurofisiológica intraoperatoria (MNIO) durante la cirugía. Conclusión: Los schwannomas del nervio intermedio son indistinguibles de los schwannomas vestibulares en la imagen preoperatoria, sin embargo, es posible identificar el origen del tumor durante la disección microquirúrgica con la ayuda de MNIO y el origen del nervio intermedio es una realidad.
\end{abstract}

Palabras clave: Nervio intermedio, Schwannoma, tumor APC.

\section{Abstract}

Background: Schwannoma of the Intermediate Nerve is rare. The most majority of cerebellopontine angle (CPA) lesions are vestibular Schwannomas. Case description: A 50-year-old woman presented with intense ear pain, facial palsy and hypoacusis. MRI revealed a CPA tumor. A left retrosigmoid approach and microsurgery was performed and the tumor origin was from the intermediate nerve. Intraoperative neurophysiologic monitoring (MNIO) was used during the surgery. Conclusion: Schwannomas of the intermediate nerve is indistinguishable from vestibular schwannomas on preoperatory image, however it's possible to identify tumor origin during microsurgery dissection with aid of MNIO and origin from intermediate nerve is a reality.

Key words: Intermediate nerve, Schwannoma, CPA tumor.

\section{Corresponding author:}

Adriana Libório

adriana_liborio@ hotmail.com 


\section{Introduction}

The intermediate nerve (IN) is described as a root containing sensory and parasympathetic fibers of the facial nerve and its fibers are found in close relation to the motor part of the facial nerve in the cerebellopontine cistern ${ }^{1,8,9}$. The first person who identified the IN was Bartholomeu Eustachius in 1563 and the first one to describe was Heinrich Albert Wirsberg in $1777^{1}$ and due to this is often referred as Wrisberg nerve ${ }^{1,9}$. It is responsible for the sense of taste in the anterior two-thirds of the tongue, floor of the mouth, palate and sensory information from the skin of the external auditory meatus as well as the lacrimal and mucous glands of the nasopharynx and nose ${ }^{1,9}$. The IN originates at the brainstem between the facial nerve and the vestibulocochlear nerve in the lateral medullopontine sulcus; the IN accompanies the facial nerve or the vestibulocochlear nerve ${ }^{2}$ and with high-resolution 3T MR imaging allows reliable depiction of the IN in some cases ${ }^{2}$.

About $10 \%$ of intracranial tumors occur in the internal auditory canal (IAC) and cerebellopontine angle (CPA) ${ }^{11}$. The vast majority $(95 \%)$ of these tumors are vestibular schwannomas, these types of tumors originate from myelin schwann cells of the vestibular portion of the vestibulocochlear nerve ${ }^{11}$. Schwannoma of the IN is rare and there are only 3 cases reported in the literature ${ }^{3,6,12}$. Although, 3 other cases with origin from IN were found in other series ${ }^{7,11}$.

\section{Case Description}

A 50-year-old woman presented with intense ear pain, facial palsy classified as House-Brackmann (HB) V/VI and hypoacusis on the left. MRI revealed an enhanced CPA lesion in the left (Figure 1).

Patient underwent microsurgical resection via left retrosigmoid approach, in semi-sitting position and intraoperative neurophysiologic monitoring (MNIO) was used during the surgery. MNIO consisted of motor evoked potentials for corticospinal tract with anodal $\mathrm{C} 3$ or C4 stimulation and recording with a pair of needles in right and left muscles $a b$ ductor pollicis brevis, anterior tibialis and abductor hallucis. Somatosensory evoked potentials after right and left median and tibial nerves stimulation resulted in normal N20 and P40 potentials. Motor evoked potentials for corticobulbar tract used $\mathrm{C} 6-\mathrm{Cz}$ assembly ${ }^{10}$ and recordings were realized in muscles of the V, VI, VII, IX, X, XI and XII nerves. Consistent muscle potentials were obtained for V, VII, IX and X nerves, which remained unchanged throughout the procedure. Free run electromyography of the same cranial muscles showed intermittent short duration type A neurotonic activity at VII and $X$ innervated muscles, promptly stopped with warm saline irrigation. Direct nerve stimulation with a bipolar probe at intensities of 0,2 and $0,4 \mathrm{~mA}$, with pulse duration of 200 US, identified V, VII and IX separately in different sites. Of remark, in the internal auditory canal, VII nerve was identified and was not the origin of the tumor.

Tumor origin was identified from the intermediate nerve (Figure 2a) and MNIO confirmed that origin was not from motor root of facial nerve. A gross total resection of tumor was achieved preserving IN, the motor portion of facial and vesti-

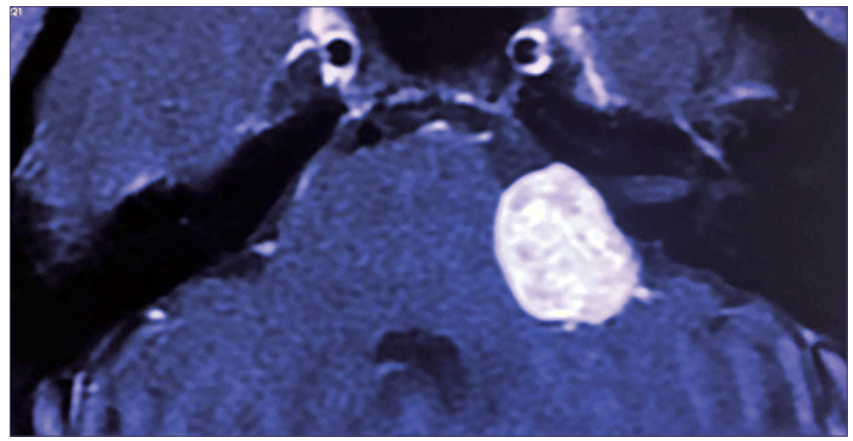

Figure 1. Axial T1-weighted MRI with gadolinium showing a lesion in the left CPA region.

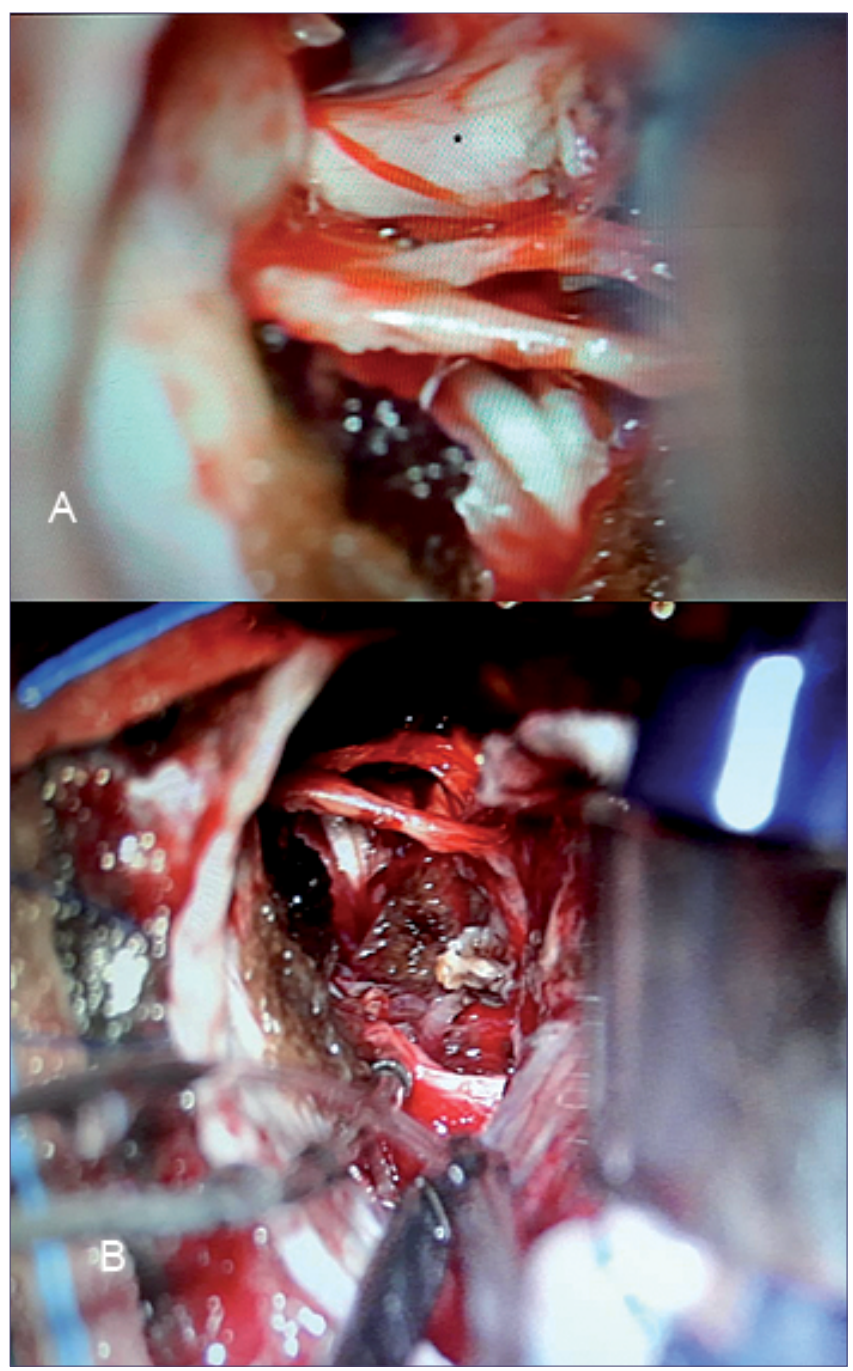

Figure 2. (a) Intraoperative image showing VII and VIII nerves and tumor arising from IN before dissection $\left[{ }^{\star}\right]$ (b) Surgical view after gross total resection of the tumor.

bulocochlear nerves. Histopathological examination confirmed schwannoma (Figure 2b, Figure 3).

The patient presented a good postoperative recovery with complete improvement in ear pain after surgery and only mild 


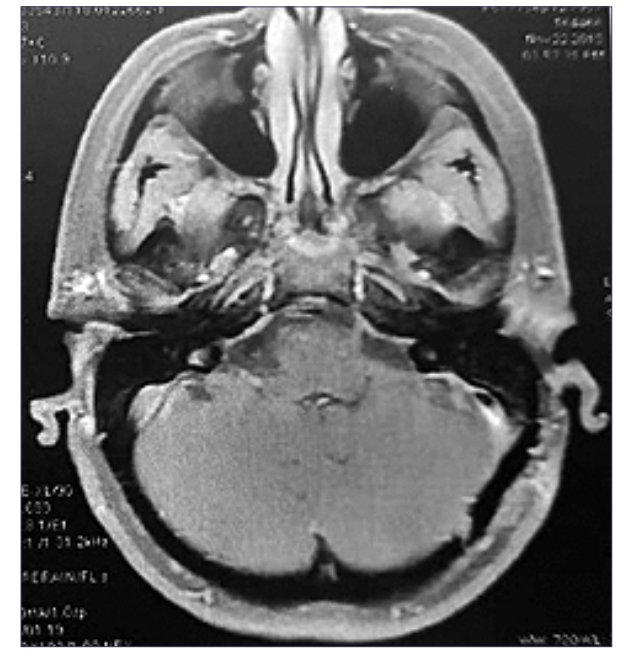

Figure 3. Post-operative axial MRI showing complete removal of the tumor.

hypoesthesia on the left face. In the $2^{\text {nd }}$ month follow up, facial nerve function had improved to HB II/VI.

\section{Discussion}

Intermediate nerve tumor is indistinguishable from vestibular or facial motor schwannoma on $\mathrm{MRI}^{5}$. Watanabe et al., reported rare tumors that mimic vestibular schwannomas in the IAC such as peripheral nerve sheath tumors, cavernous hemangiomas, facial motor schwannomas, meningiomas and also schwannoma of the intermediate nerve ${ }^{11}$ and they also cited glioblastoma multiforme, metastases, primary adenocarcinoma, arachnoid cysts, lipomas, lipochoristoma, melanoma from another series ${ }^{11}$ which is important to neurosurgeon to keep in mind.

With advances in MRI neuroimaging technology, an increasing number of asymptomatic smaller tumors localized to the IAC are being detected. In case of intermediate nerve section or compression, loss of lacrimation, decreased sensation in the posterior aspect of the external auditory canal, known as the Hitselberger sign, can occur. It is considered an early sign of tumor presence at IAC ${ }^{1}$. When small sized tumors grow and become more symptomatic, they are often treated with radiosurgery without histologic confirmation. However, if tumors grow and symptoms progress enough, microsurgery is required ${ }^{4,11}$.

During surgery, the facial motor, intermediate nerve, vestibulocochlear and other cranial nerves can be identified by direct nerve stimulation ${ }^{3,6,7,9}$. The stimulation of the intermedius nerve gives no potential, since it is a sensory nerve. On the other hand, the facial nerve stimulation results in a muscle action potential. This simple technique is used to help identify them both, like in our case.

The operative approaches that can be used are retrosigmoid, translabyrinthine, suboccipital or subtemporal. In cases of schwannoma of the $\mathrm{NI}$ found in the literature, the retrosigmoid approach ${ }^{6,11}$ and the suboccipital craniotomy were performed $^{3,7}$. In our patient, we performed the retrosigmoid approach with good route and total resection.

\section{Conclusion}

Schwannoma of the intermediate nerve is rare. When there is a tumor arising from this nerve it cannot be differentiated from vestibular or facial schwannomas by imaging. However, the identification of the origin of tumor from IN is possible during microsurgery dissection with direct stimulation and, also, symptoms can suggest the diagnosis. It is worthy to keep in mind that schwannoma of the IN is a possibility.

Conflict of Interest: None.

\section{References}

1. Alfieri A, Strauss C, Prell J, Peschke E. History of the nervus intermedius of Wrisberg. Ann Anat. 2010;192(3):139-144. doi:10.1016/j.aanat.2010.02.004

2. Burmeister HP, Baltzer PA, Dietzel M, et al. Identification of the nervus intermedius using $3 \mathrm{~T}$ MR imaging. Am J Neuroradiol. 2011;32(3):460-464. doi:10.3174/ajnr.A2338

3. Kudo A, Suzuki M, Kubo N, Kuroda K, Ogawa A, Iwasaki Y. Schwannoma arising from the intermediate nerve and manifesting as hemifacial spasm. J Neurosurg. 2009;84(2):277-279. doi:10.3171/jns.1996.84.2.0277

4. Noonan KY, Rang C, Callahan K, Simmons NE, Erkmen K, Saunders JE. Nervus Intermedius Symptoms following Surgical or Radiation Therapy for Vestibular Schwannoma. Otolaryngol - Head Neck Surg (United States). 2016;155(4):657-662. doi:10.1177/0194599816655144

5. Rodgers B, Chamoun R, Newell K, Lin J. Nervus intermedius meningioma. J Laryngol Otol. 2014;128(6):543-546. doi:10.1017/ S0022215114000851

6. Scheller C, Rachinger J, Prell J, Kornhuber M, Strauss C. Schwannoma of the intermediate nerve. J Neurosurg. 2008;109(1):144-148. doi:10.3171/jns/2008/109/7/0144

7. Sherman JD, Dagnew E, Pensak ML, et al. Facial nerve neuromas: Report of 10 cases and review of the literature. Neurosurgery. 2002;50(3):450-456. doi:10.1097/00006123-200203000-00004

8. Tamura M, Murata N, Hayashi M, Regis J. Injury of the lacrimal component of the nervus intermedius function after radiosurgery versus microsurgery. Neurochirurgie. 2004;50(2-3 Pt 2):338-344. doi:MDOINCHIR-06-2004-50-2-3-C2-0028-3770-101019-ART18 [pii]

9. Tubbs RS, Steck DT, Mortazavi MM, Cohen-Gadol AA. The nervus intermedius: A review of its anatomy, function, pathology, and role in neurosurgery. World Neurosurg. 2013;79(5-6):763767. doi:10.1016/j.wneu.2012.03.023

10. Verst SM, Chung TM, Sucena AC, Maldaun VC, Aguiar PHP. Comparison between the $\mathrm{C} 5$ or $\mathrm{C} 6-\mathrm{Cz}$ electrode assembly and C3 or C4-Cz assembly for transcranial electric motor activation of muscular response of the contralateral facial nerve. Acta Neurochir. 2012;154(12):2229-2235. doi:10.1007/s00701-012-1505-z

11. Watanabe K, In-Ping Huang Cobb M, Zomorodi AR, et al. Rare Lesions of the Internal Auditory Canal. World Neurosurg. 2017;99:200-209. doi:10.1016/j.wneu.2016.12.003

12. Hosoya M, Oishi N, Noguchi M, Kasuya K, Nishiyama T, Ishikawa $T$, et al. Intraoperative Facial Nerve Monitoring Revealed the Origin of Rapidly Progressing Schwannoma in the Cerebellopontine Angle: A Case of Large Intermediate Nerve Schwannoma. J Int Adv Otol 2018; 14(3): 488-92. 